\title{
Two Cases of Hepatocellular Carcinoma Arising Over 20 Years after a Sustained Virologic Response Following Interferon Therapy for Chronic Hepatitis C
}

\author{
Kazuhide Takata ${ }^{1}$, Fuminori Ishii ${ }^{2}$, Yotaro Uchida ${ }^{1}$, Hiromi Fukuda ${ }^{1}$, Ryo Yamauchi ${ }^{1}$, \\ Kaoru Umeda ${ }^{1}$, Naoaki Tsuchiya ${ }^{1}$, Takashi Tanaka ${ }^{1}$, Keiji Yokoyama ${ }^{1}$, Daisuke Morihara ${ }^{1}$, \\ Yasuaki Takeyama ${ }^{1}$, Satoshi Shakado ${ }^{1}$, Shotaro Sakisaka ${ }^{1}$ and Fumihito Hirai ${ }^{1}$
}

\begin{abstract}
:
The development of hepatocellular carcinoma (HCC) after a sustained virologic response (SVR) due to interferon (IFN) therapy for hepatitis $\mathrm{C}$ virus infection remains a serious problem. We herein report 2 cases of HCC that developed more than 20 years after SVR with IFN therapy for chronic hepatitis C. The patients were 89- and 72-year-old men with HCC that developed 24-25 years after an SVR with IFN therapy. These patients regularly underwent imaging examinations; therefore, the HCC was detected in the early stage, when it was still curable. Both cases suggest that long-term surveillance after an SVR is effective for the detection of $\mathrm{HCC}$, and radical treatment is possible.
\end{abstract}

Key words: hepatocellular carcinoma, interferon therapy, sustained virologic response

(Intern Med 59: 1855-1860, 2020)

(DOI: 10.2169/internalmedicine.4479-20)

\section{Introduction}

Hepatitis $\mathrm{C}$ virus (HCV) is a major cause of chronic hepatitis, liver cirrhosis, and hepatocellular carcinoma (HCC) worldwide. Since 1992, patients with chronic hepatitis $\mathrm{C}(\mathrm{CHC})$ have been administered interferon (IFN) treatment. A sustained virologic response (SVR) during successful IFN therapy reduces the incidence of de novo $\mathrm{HCC}$, although it is not completely suppressed (1-5). The incidence of HCC over 10 years and even more than 20 years after an SVR have been reported $(6,7)$. Therefore, long-term cancer surveillance is required after an SVR for early HCC detection at a curable stage; however, no consensus has been reached concerning how long such monitoring should continue.

\section{Case Reports}

\section{Case 1}

An 89-year-old man was referred to our hospital for the further investigation of a liver tumor. His medical history included type 2 diabetes mellitus treated with metformin and treatment with IFN-alpha 3 times a week for 24 weeks for CHC at a local hospital with achievement of an SVR at 65 years of age. After achieving an SVR, he had been followed up with regular ultrasonography (US) once every six months by his primary care physician. He had a history of alcohol intake of about $10 \mathrm{~g}$ per day for over 20 years.

$\mathrm{He}$ was asymptomatic, and the physical findings were normal. His body mass index (BMI) was $20.2 \mathrm{~kg} / \mathrm{m}^{2}$. Laboratory tests showed normal serum liver enzyme levels and an elevated glucose level suggesting known diabetes (glucose $142 \mathrm{mg} / \mathrm{dL}, \mathrm{HbA} 1 \mathrm{c}$ 7.4\%). Tumor marker levels were

${ }^{1}$ Department of Gastroenterology and Medicine, Fukuoka University Faculty of Medicine, Japan and ${ }^{2}$ Department of Gastroenterological Surgery, Fukuoka University Faculty of Medicine, Japan

Received: January 14, 2020; Accepted: March 10, 2020; Advance Publication by J-STAGE: April 30, 2020

Correspondence to Dr. Kazuhide Takata, edihuzak_t@yahoo.co.jp 
Table 1. Laboratory Data after Development of Hepatocellular Carcinoma.

\begin{tabular}{|c|c|c|}
\hline & Case 1 & Case 2 \\
\hline White blood cell & 6,300 & $3,100 / \mu \mathrm{L}$ \\
\hline Red blood cell & 403 & $31110^{6} / \mu \mathrm{L}$ \\
\hline Hemoglobin & 12.8 & $10.8 \mathrm{~g} / \mathrm{dL}$ \\
\hline Platelets & 249 & $10910^{3} / \mu \mathrm{L}$ \\
\hline PT & 98 & $77 \%$ \\
\hline PT-INR & 1.01 & 1.12 \\
\hline Albumin & 4.1 & $3.7 \mathrm{~g} / \mathrm{dL}$ \\
\hline Total bilirubin & 0.8 & $0.5 \mathrm{mg} / \mathrm{dL}$ \\
\hline AST & 16 & $27 \mathrm{IU} / \mathrm{L}$ \\
\hline ALT & 9 & $25 \mathrm{IU} / \mathrm{L}$ \\
\hline GGT & 25 & $50 \mathrm{IU} / \mathrm{L}$ \\
\hline ALP & 254 & $216 \mathrm{IU} / \mathrm{L}$ \\
\hline BUN & 16 & $11 \mathrm{mg} / \mathrm{dL}$ \\
\hline Creatinine & 1.05 & $0.73 \mathrm{mg} / \mathrm{dL}$ \\
\hline eGFR & 50.7 & $80.2 \mathrm{~mL} / \mathrm{min}$ \\
\hline Ferritin & 280 & $\mathrm{ND}$ ng/mL \\
\hline Glucose & 142 & $88 \mathrm{mg} / \mathrm{dL}$ \\
\hline $\mathrm{HbA1c}$ & 7.4 & $5.4 \%$ \\
\hline Insulin & 2.4 & $\mathrm{ND} \mu \mathrm{U} / \mathrm{mL}$ \\
\hline HOMA-IR & 0.84 & ND \\
\hline M2BpGi & (1+) 1.42 & (-) $0.68 \mathrm{COI}$ \\
\hline hyaluronic acid & 32.1 & $135.1 \mathrm{ng} / \mathrm{mL}$ \\
\hline Type IV collagen 7S & 4.6 & $4.7 \mathrm{ng} / \mathrm{mL}$ \\
\hline \multicolumn{3}{|l|}{ Infectious Makers } \\
\hline $\mathrm{HCVAb}$ & (+) 7.9 & (+) $5.6 \mathrm{COI}$ \\
\hline HCV-RNA & not detected & not detected \\
\hline HBsAg & $(-)$ & $(-)$ \\
\hline $\mathrm{HBsAb}$ & $(-)$ & $(-)$ \\
\hline $\mathrm{HBcAb}$ & (+) 0.014 & $(-) \mathrm{COI}$ \\
\hline $\mathrm{HBcrAg}$ & $<3.0$ & ND $\log U / m L$ \\
\hline HBV-DNA & not detected & ND \\
\hline \multicolumn{3}{|l|}{ Tumor Makers } \\
\hline AFP & 7.2 & $3.0 \mathrm{ng} / \mathrm{mL}$ \\
\hline AFP L3 & 12.8 & ND $\%$ \\
\hline DCP & 15 & $56 \mathrm{mAU} / \mathrm{mL}$ \\
\hline \multicolumn{3}{|c|}{$\begin{array}{l}\text { AST: aspartate aminotransferase, ALT: alanine aminotransferase, } \\
\text { GGT: gamma-glutamyl transferase, ALP: alkaline phosphatase, BUN } \\
\text { urea nitrogen, eGFR: estimated glomerular filtration rate, HOMA-IR: } \\
\text { homeostasis model assessment of insulin resistance, M2BPGi: Mac-2 } \\
\text { binding protein glycosylation isomer, HCVAb: hepatitis C virus anti- } \\
\text { body, HBsAg: hepatitis B surface antigen, HBsAb: hepatitis B surface } \\
\text { antibody, HBcAb: hepatitis B core antibody, HBcrAg: hepatitis B } \\
\text { core-related antigen, AFP: alphafetoprotein, DCP: des- } \gamma \text {-carboxy pro- } \\
\text { thrombin, ND: no data }\end{array}$} \\
\hline
\end{tabular}

normal except for lens culinaris agglutinin-reactive fraction of alphafetoprotein (AFP-L3), (AFP, $7.2 \mathrm{ng} / \mathrm{mL}$; AFP-L3, $12.8 \%$, range $<10 \%$; des- $\gamma$-carboxy prothrombin, $15 \mathrm{mAU} /$ $\mathrm{mL})$. No fibrosis markers showed prominent elevation [Mac2 binding protein glycosylation isomer (M2BPGi), 1.42 COI; hyaluronic acid, $32.1 \mathrm{ng} / \mathrm{mL}$ ]. The serum HCV-RNA level was not detected. The hepatitis B core antibody test was positive; however, hepatitis B surface antigen, hepatitis B surface antibody, hepatitis B core-related antigen, and hepatitis B virus (HBV) DNA were negative (Table 1).
Abdominal US revealed a 20-mm lesion with low echogenicity in segment 5 of the liver that had not been present 6 months earlier (Fig. 1a); this nodule exhibited the characteristics of HCC on gadolinium ethoxybenzyl diethylenetriamine pentaacetic acid-enhanced magnetic resonance imaging (EOB-MRI) (Fig. 1b, c). According to a needle biopsy specimen, the tumor was histologically confirmed to be well to moderately differentiated HCC arising from the liver without inflammation and fibrosis (Fig. 2a, b). In addition, HBV cccDNA was not detected in hepatocytes. Radiofrequency ablation was performed, which provided good results, and no recurrence has been observed on follow-up.

\section{Case 2}

A 72-year-old man was referred to our hospital for the further investigation of a liver tumor that was detected coincidentally by follow-up computing tomography (CT) after surgery for esophageal cancer. His medical history included treatment with IFN-alpha 3 times a week for 24 weeks for CHC resulting in an SVR at 47 years of age. After achieving an SVR, he had not received regular cancer surveillance, although he had been followed up with regular CT once every 6 months after subtotal esophagectomy for esophageal cancer at 70 years of age. He had a history of alcohol intake of about $100 \mathrm{~g}$ per day for over 30 years until esophageal cancer was diagnosed.

$\mathrm{He}$ was asymptomatic, and the physical findings were normal except for a chest operative scar. His BMI was 18.8 $\mathrm{kg} / \mathrm{m}^{2}$. Laboratory tests showed normal serum liver enzyme levels and elevated des- $\gamma$-carboxy prothrombin (DCP) level (84 mAU/mL). Serum HCV-RNA level was not detected (Table 1).

Contrast-enhanced CT and EOB-MRI revealed a 20-mm nodule with early-phase enhancement in segment 8 of the liver, suggesting an HCC diagnosis, that had not been present 6 months earlier (Fig. 3a). He underwent subsegmental resection of the liver. Upon a histological examination, the tumor was diagnosed as poorly differentiated HCC arising from the liver with severe fibrosis (Fig. 4a, b). The patient's postoperative course was uneventful, and no recurrence has been observed on follow-up.

\section{Discussion}

The clinical courses of these patients provide two important clinical points. The first is that HCC can develop even more than 20 years after achieving an SVR. Previous studies have demonstrated how successful IFN treatment for $\mathrm{CHC}$ results in improvement of liver inflammation and hepatic fibrosis and decrease in the incidence of HCC (1-5). However, numerous patients have developed HCC after an SVR, and these cases should not be underestimated. The 5- and 10-year cumulative carcinogenic rates were $2.3-8.8 \%$ and $3.1-11.1 \%$, respectively (7). However, the rate after more than 10 years is unclear, and there have been only a few reports of carcinogenesis after 20 years or more (Ta- 

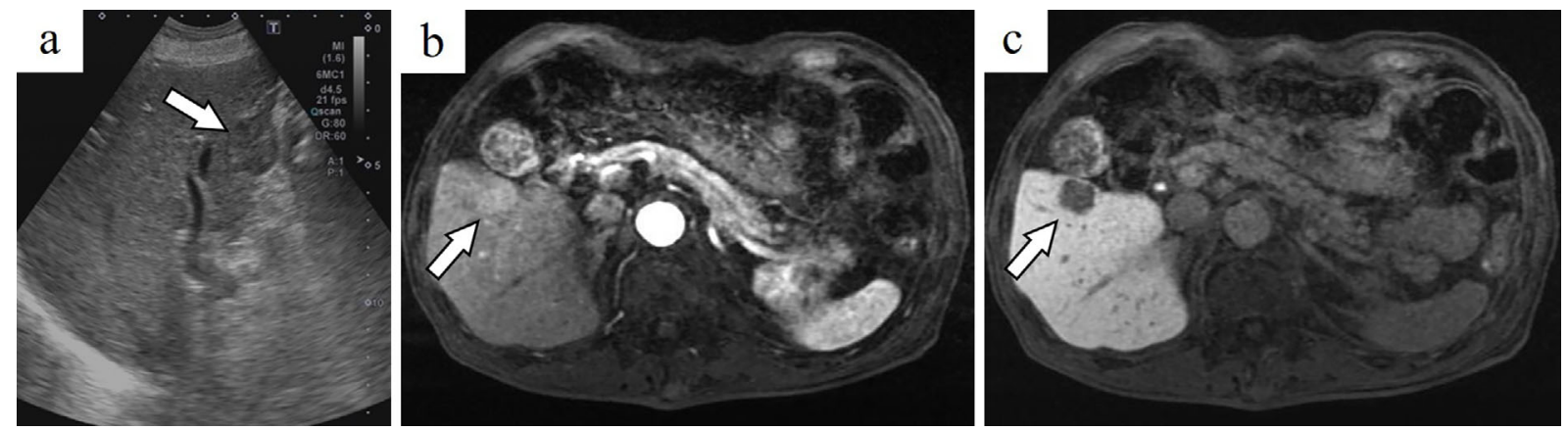

Figure 1. Image findings in case 1. (a) Ultrasonography revealed that the tumor (segment 5) exhibited low echogenicity (arrow). (b, c) The tumor (arrow) showed hyperintensity in the early phase of gadolinium ethoxybenzyl diethylenetriamine pentaacetic acid-enhanced MRI and clear hypointensity in the hepatobiliary phase.
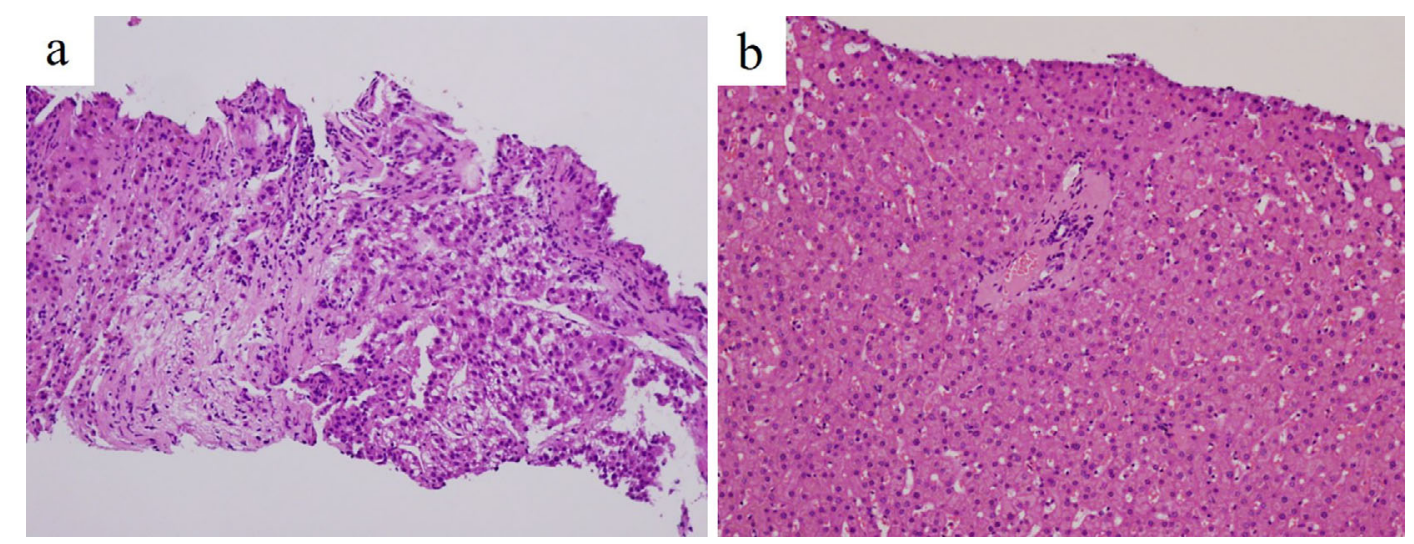

Figure 2. Histological findings of the liver biopsy in Case 1. (a) The biopsy specimen from the tumor nodule was confirmed to be well to moderately differentiated hepatocellular carcinoma [Hematoxylin and Eosin $(H \& E)$ staining, $\times 100]$. (b) The biopsy specimen from the non-tumor area showed no steatosis and was classified as F0, A0, according to the New Inuyama Classification of hepatitis activity grading (H\&E staining, $\times \mathbf{2 0 0})$.

ble 2) (7-12).

Hepatocarcinogenesis after an SVR is associated with risk factors other than carcinogenicity due to HCV. Well-known major risk factors for developing HCC after an SVR are male sex, age exceeding 50 years old, and F3 or F4 fibrotic stage at the time of IFN introduction (13). However, these are risk factors for hepatocarcinogenesis occurring within 10 years after having an SVR. It is expected that the longer the time after an SVR, the greater the extent that carcinogenesis is influenced by aging and lifestyle-related factors, such as alcohol consumption, metabolic disorders such as diabetes and insulin resistance, liver steatosis, and nonalcoholic steatohepatitis (NASH) $(7,14)$.

Of the 9 reported cases of carcinogenesis occurring over 20 years after an SVR, including our own cases, all patients were men, and 6 of them $(66.7 \%)$ were over 50 years old at the time of the IFN treatment. In Case 1, hepatic fibrosis was not observed at the onset of HCC. Although it was difficult to determine the status of liver fibrosis before IFN treatment due to the absence of any liver tissue specimens, the long-term SVR through successful IFN therapy might thus have improved the degree of hepatic fibrosis in this patient. In contrast, in Case 2, advanced hepatic fibrosis, possibly due to his alcohol consumption, was observed at the onset of HCC. In Case 1, the patient was diabetic, although there was no steatosis suggesting NASH. In addition, although latent HBV infection, which is associated with carcinogenesis after an SVR (15), was suspected, a test for HBV cccDNA in the liver tissue was negative; therefore, its association with the carcinogenesis of HCC is unlikely.

Some previously reported cases of carcinogenesis detected over 20 years after an SVR were detected in an advanced stage with a large HCC that might have first manifested several years earlier. However, in both of the present cases, HCC had not been noted on imaging examinations performed just six months before the HCC detection, suggesting de novo carcinogenesis over 20 years after achieving an SVR.

The second important clinical point suggested by the present findings is that long-term monitoring after achieving an SVR is crucial. In Case 1, the patient had been followed-up for a long time with regular imaging examinations, resulting 

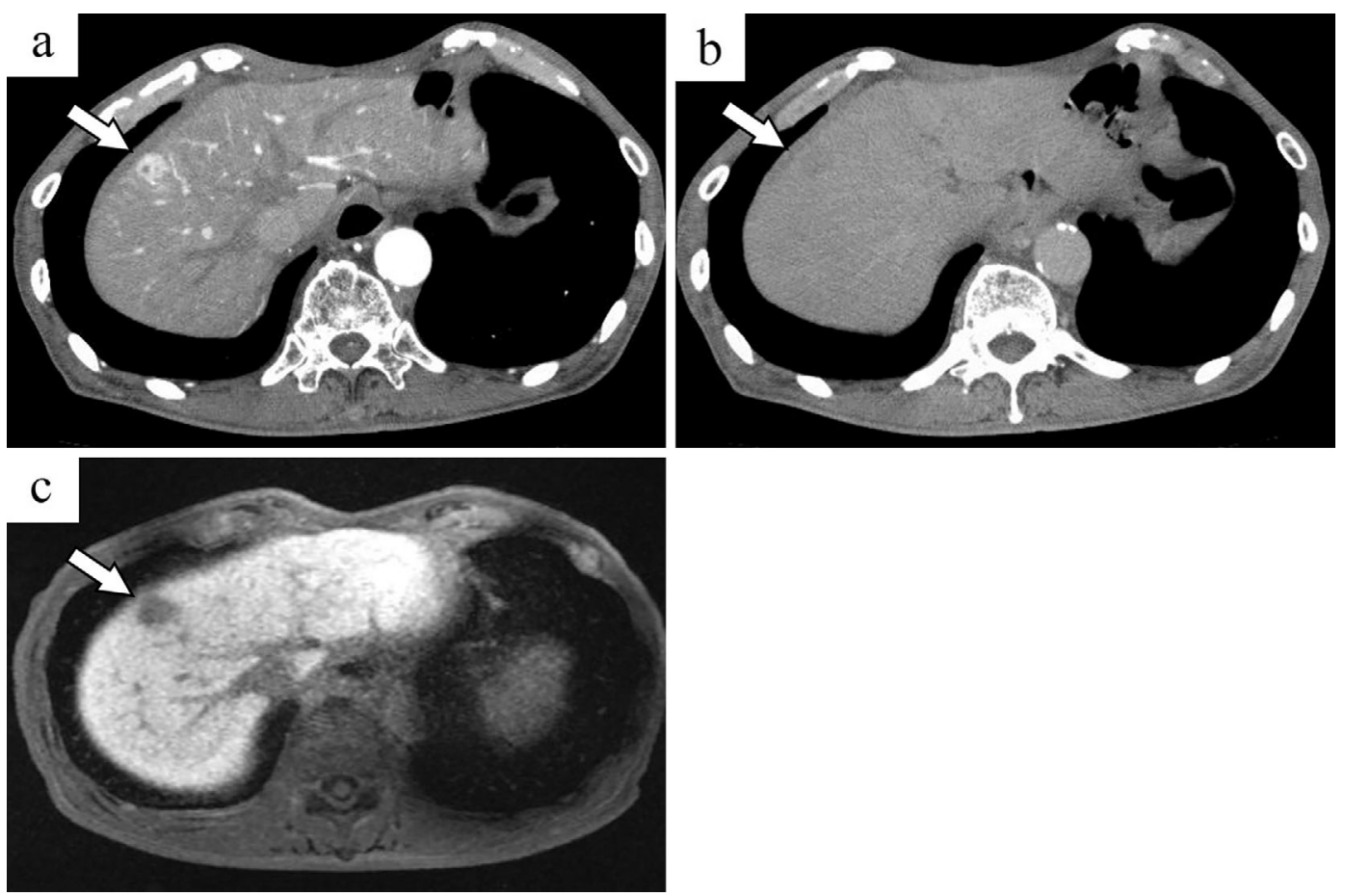

Figure 3. Image findings in case 2. (a, b) Early-phase computed tomography revealed hyperenhancement and a decrease to hypoenhancement in late-phase computed tomography. (c) The tumor (arrow) showed hypointensity in the hepatobiliary phase of gadolinium ethoxybenzyl diethylenetriamine pentaacetic acid-enhanced MRI.
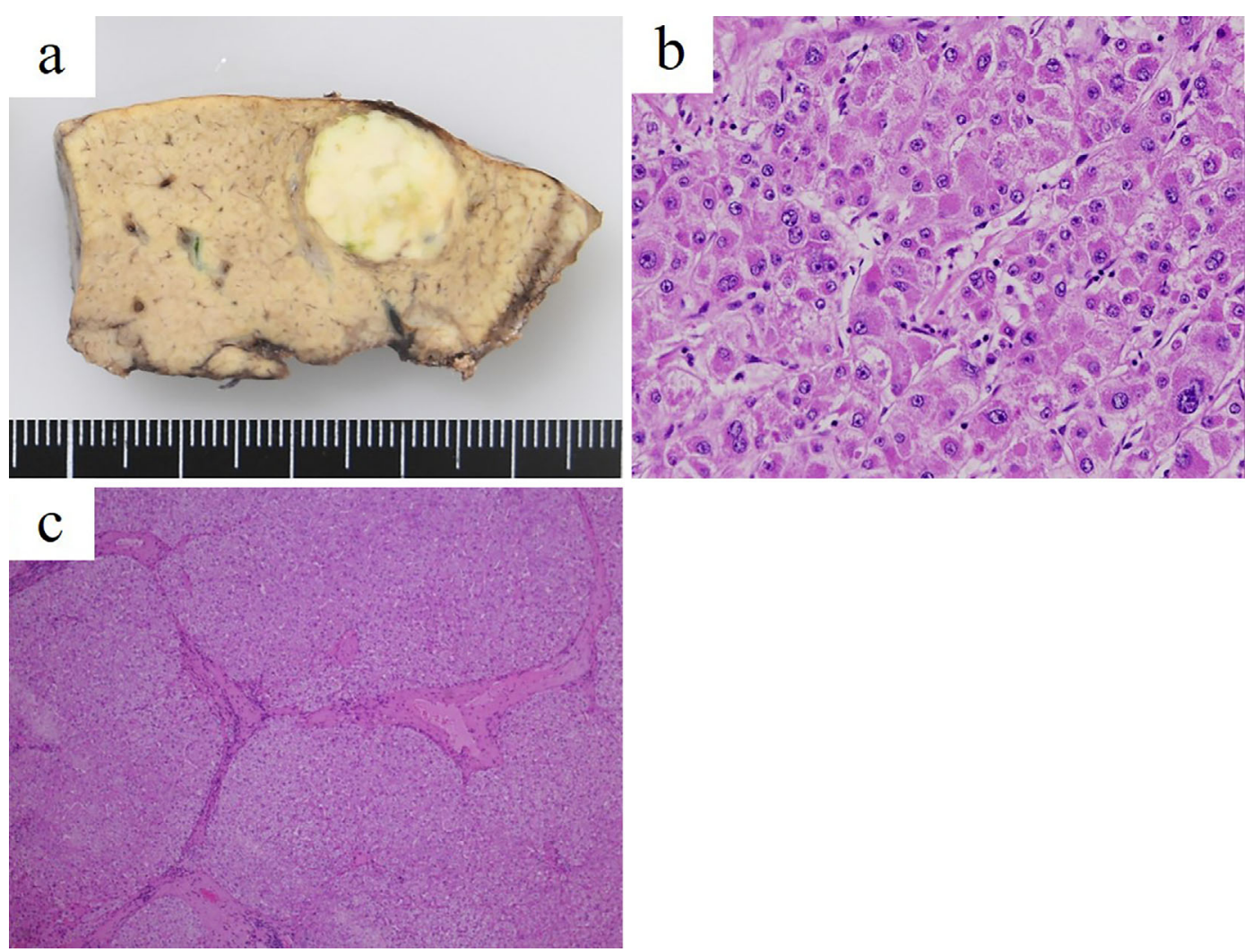

Figure 4. Histological findings of the resected liver specimen in case 2. (a) Macroscopically, the cutsurface reveals the mass lesion of the liver. (b) The specimen from the tumor nodule was confirmed to be poorly differentiated hepatocellular carcinoma [Hematoxylin and Eosin (H\&E) staining, ×400]. (c) The specimen from the non-tumor area showed no steatosis and was classified as F3, A0, according to the New Inuyama Classification of hepatitis activity grading (H\&E staining, $\times 40)$. 
Table 2. Previous Reports of Hepatocellular Carcinoma Occurrence 20 Years or More after an SVR Including Our Cases.

\begin{tabular}{|c|c|c|c|c|c|c|c|c|c|c|c|c|c|c|}
\hline \multirow{2}{*}{ Reference } & \multicolumn{2}{|r|}{ Age } & \multirow{2}{*}{$\begin{array}{l}\text { Intervals } \\
\text { (years) }\end{array}$} & \multirow{2}{*}{ Sex } & \multirow{2}{*}{$\begin{array}{c}\text { Ethanol } \\
\text { (g/day) }\end{array}$} & \multirow{2}{*}{$\mathrm{DM}$} & \multirow{2}{*}{ Steatosis } & \multirow{2}{*}{$\mathrm{HBcAb}$} & \multirow{2}{*}{$\begin{array}{c}\text { AFP } \\
(\mathrm{ng} / \mathrm{mL})\end{array}$} & \multirow{2}{*}{$\begin{array}{c}\begin{array}{c}\text { Histology } \\
\text { at HCC }\end{array} \\
\text { occurrence }\end{array}$} & \multicolumn{3}{|c|}{$\mathrm{HCC}$} & \multirow{2}{*}{ Treatment } \\
\hline & $\begin{array}{l}\text { at } \\
\text { SVR }\end{array}$ & $\begin{array}{c}\text { at HCC } \\
\text { occurrence }\end{array}$ & & & & & & & & & Histology & $\begin{array}{c}\text { BCLC } \\
\text { stage }\end{array}$ & $\begin{array}{c}\text { Size } \\
\text { maximum } \\
(\mathrm{cm})\end{array}$ & \\
\hline 8 & 63 & 83 & 20 & M & 0 & $(-)$ & $(-)$ & $(-)$ & 4.5 & N/A & N/A & N/A & 6.0 & HR \\
\hline 9 & 46 & 66 & 20 & M & $4-6$ & $(-)$ & N/A & N/A & 3.0 & N/A & mode-poor & A & 9.5 & HR \\
\hline 9 & 61 & 82 & 20 & M & 0 & $(-)$ & N/A & N/A & 1.8 & N/A & N/A & A & 2.0 & TACE \\
\hline 10 & 55 & 75 & 20 & M & 0 & $(-)$ & N/A & N/A & 538 & N/A & N/A & $\mathrm{C}$ & 2.0 & TKI \\
\hline 11 & 66 & 86 & 20 & M & 20 & $(-)$ & $\mathrm{N} / \mathrm{A}$ & $(+)$ & 2.4 & $2 / 0$ & N/A & $\mathrm{A}$ & 1.5 & $\begin{array}{c}\text { TACE+ } \\
\text { RFA }\end{array}$ \\
\hline 12 & 43 & 63 & 20 & M & 0 & $(-)$ & $(+)$ & N/A & 459.8 & $0 / 0$ & mode & $\mathrm{C}$ & 6.4 & HR \\
\hline 7 & 58 & 82 & 24 & M & 100 & $(-)$ & $(-)$ & $(+)$ & 7,060 & N/A & N/A & $\mathrm{C}$ & 8.0 & TACE \\
\hline our case 1 & 65 & 89 & 24 & M & 10 & $(+)$ & $(-)$ & $(+)$ & 7.2 & $0 / 0$ & well-mode & A & 2.0 & RFA \\
\hline our case 2 & 47 & 72 & 25 & M & 100 & $(-)$ & $(-)$ & $(-)$ & 3.3 & $3 / 0$ & poor & A & 1.7 & HR \\
\hline
\end{tabular}

SVR: sustained virologic response, HCC: hepatocellular carcinoma, DM: diabetes mellitus, AFP: alphafetoprotein, HR: hepatic resection, TACE: transcatheter arterial chemoembolization, TKI: tyrosine kinase inhibitor, RFA: radiofrequency ablation, N/A: not applicable

in curable treatment for early stage HCC. In contrast, Case 2 had not been followed up after achieving an SVR, although regular imaging examinations as follow-up for other diseases fortunately led to the detection of HCC at a curable clinical stage. Furthermore, in both cases, the expected time of carcinogenesis was revealed through regular imaging surveillance.

Successful IFN treatment is known to improve the prognosis of patients with $\mathrm{CHC}$ by suppressing the incidence of HCC and preventing the progression of liver fibrosis. In addition, preserving the liver function by achieving an SVR enables radical treatment for HCC to be performed, resulting in a favorable prognosis (16-18). Several studies have recently addressed the association between a lack of surveillance after an SVR and more advanced HCC at detection, resulting in a poor prognosis (19-21). However, there are currently no prospective studies on effective surveillance methods for early HCC detection after an SVR, including imaging intervals and discontinuation timing.

Recently, with the advent of direct-acting antiviral (DAA) treatment, the number of patients achieving SVR has increased dramatically. Whether or not SVR due to DAA treatment reduces the carcinogenicity of HCC development remains controversial; however, the importance of surveillance after an SVR is increasing $(22,23)$. Therefore, further studies are needed to evaluate the efficacy of future surveillance methods.

As HCC can develop over 20 years after achieving an SVR, long-term cancer surveillance is crucial for ensuring a favorable patient prognosis.

The authors state that they have no Conflict of Interest (COI).

\section{Acknowledgement}

We are indebted to Dr. Yoshihiro Hamada and Prof. Kazuki Nabeshima, Department of Pathology at Fukuoka University
Hospital, for providing histological information and Dr. Wako Yoshimitsu, Postgraduate Clinical Training Center at Fukuoka University Hospital, for the valuable support.

\section{References}

1. Yoshida H, Arakawa Y, Sata M, et al. Interferon therapy prolonged life expectancy among chronic hepatitis C patients. Gastroenterology 123: 483-491, 2002.

2. Yoshida H, Shiratori Y, Moriyama M, et al. Interferon therapy reduces the risk for hepatocellular carcinoma: national surveillance program of cirrhotic and noncirrhotic patients with chronic hepatitis C in Japan. IHIT Study Group. Inhibition of Hepatocarcinogenesis by Interferon Therapy. Ann Intern Med 131: 174-181, 1999.

3. Okanoue T, Itoh Y, Minami M, et al. Interferon therapy lowers the rate of progression to hepatocellular carcinoma in chronic hepatitis $\mathrm{C}$ but not significantly in an advanced stage: a retrospective study in 1148 patients. Viral Hepatitis Therapy Study Group. J Hepatol 30: 653-659, 1999.

4. Nishiguchi S, Kuroki T, Nakatani S, et al. Randomised trial of effects of interferon-alpha on incidence of hepatocellular carcinoma in chronic active hepatitis $C$ with cirrhosis. Lancet 346: 10511055, 1995.

5. Morgan RL, Baack B, Smith BD, Yartel A, Pitasi M, Falck-Ytter Y. Eradication of hepatitis $C$ virus infection and the development of hepatocellular carcinoma: a meta-analysis of observational studies. Ann Intern Med 158: 329-337, 2013.

6. Saito M, Seo Y, Yano Y, et al. Development of a hepatocellular carcinoma in a chronic hepatitis $\mathrm{C}$ patient 18 years after achieving a sustained virological response to interferon therapy: case report and literature review. Clin J Gastroenterol 5: 119-126, 2012.

7. Yoshida Y, Yonezawa M, Okamoto T, et al. Occurrence of hepatocellular carcinoma 24 years after successful interferon therapy in a patient with chronic hepatitis C: a case report. Clin J Gastroenterol 12: 120-127, 2019.

8. Nakayama H, Iketani S, Okamoto D, et al. Long-term prognosis of patients with chronic hepatitis $\mathrm{C}$ who developed hepatocellular carcinoma after a sustained response to interferon therapy. Iwaki Kyoritsu Byoin Ihou (J Iwaki Kyoritsu Gen Hosp) 34: 12-21, 2013 (in Japanese).

9. Igarashi G, Endo T, Sawada N, et al. Development of hepatocellu- 
lar carcinoma in chronic hepatitis c patients 20 years after achieving a sustained virological response with interferon therapy: a report of two cases. J Gen Fam Med 16: 199-203, 2015.

10. Harai S, Kuratomi N, Fukazawa Y, et al. A case of hepatocellular carcinoma with portal vein tumor thrombosis and bone metastasis developed 20 years after successful interferon therapy to hepatitis C. Yamanashi Kenritsu Chuo Byoin Nenpo (J Yamanashi-ken Central Hosp) 41: 68-70, 2015 (in Japanese).

11. Okabe J, Fukuda K, Iwamoto T, et al. A case of cirrhosis with hepatitis $\mathrm{C}$ virus infection developing hepatocellular carcinoma 20 years after achieving sustained virological response to interferon therapy. Kanzo (Acta Hepatol Jpn) 57: 27-33, 2016 (in Japanese, Abstract in English).

12. Hirohata Y, Yoh Y, Nakamura Y, Kato T, Okamura R. Surgical treatment for hepatocellular carcinoma in a chronic hepatitis $\mathrm{C} \mathrm{pa-}$ tient 20 years after achieving a sustained virological response. Nippon Shokaki Geka Gakkai Zasshi (Jpn J Gastroenterol Surg) 50: 528-534, 2017 (in Japanese, Abstract in English).

13. Makiyama A, Itoh $\mathrm{Y}$, Kasahara $\mathrm{A}$, et al. Characteristics of patients with chronic hepatitis $\mathrm{C}$ who develop hepatocellular carcinoma after a sustained response to interferon therapy. Cancer 101: 16161622, 2004

14. Nirei K, Matsumura H, Kumakawa $M$, et al. Steatosis influences the clinical profiles and long-term outcomes of interferon-treated chronic hepatitis $\mathrm{C}$ and liver cirrhosis patients. Int J Med Sci $\mathbf{1 4}$ 45-52, 2017.

15. Ikeda K, Marusawa H, Osaki Y, et al. Antibody to hepatitis B core antigen and risk for hepatitis C-related hepatocellular carcinoma: a prospective study. Ann Int Med 146: 649-656, 2007.

16. Koda M, Tanaka S, Takemura S, et al. Long-term prognostic factors after hepatic resection for hepatitis c virus-related hepatocellular carcinoma, with a special reference to viral status. Liver Cancer 7: 261-276, 2018.
17. Uenishi T, Kubo S, Hirohashi K, et al. Relationship between response to previous interferon therapy and postoperative recurrence of hepatitis C virus-related hepatocellular carcinoma. Hepatol Res 24: 404-412, 2002.

18. Ikeda K, Kobayashi M, Saitoh S, et al. Recurrence rate and prognosis of patients with hepatocellular carcinoma that developed after elimination of hepatitis C virus RNA by interferon therapy. A closed cohort study including matched control patients. Oncology 65: 204-210, 2003.

19. Toyoda $\mathrm{H}$, Tada $\mathrm{T}$, Tsuji $\mathrm{K}$, et al. Characteristics and prognosis of hepatocellular carcinoma detected in patients with chronic hepatitis $\mathrm{C}$ after the eradication of hepatitis $\mathrm{C}$ virus: a multicenter study from Japan. Hepatol Res 46: 734-742, 2016.

20. Yamashita N, Ohho A, Yamasaki A, Kurokawa M, Kotoh K, Kajiwara E. Hepatocarcinogenesis in chronic hepatitis C patients achieving a sustained virological response to interferon: significance of lifelong periodic cancer screening for improving outcomes. J Gastroenterol 49: 1504-1513, 2014.

21. Na SK, Song BC. Development and surveillance of hepatocellular carcinoma in patients with sustained virologic response after antiviral therapy for chronic hepatitis C. Clin Mol Hepatol 25: 234224, 2019.

22. Kobayashi M, Suzuki F, Fujiyama S, et al. Sustained virologic response by direct antiviral agents reduces the incidence of hepatocellular carcinoma in patients with $\mathrm{HCV}$ infection. J Med Virol 89: 476-483, 2017

23. Conti F, Buonfiglioli F, Scuteri A, et al. Early occurrence and recurrence of hepatocellular carcinoma in HCV-related cirrhosis treated with direct-acting antivirals. J Hepatol 65: 727-733, 2016.

The Internal Medicine is an Open Access journal distributed under the Creative Commons Attribution-NonCommercial-NoDerivatives 4.0 International License. To view the details of this license, please visit (https://creativecommons.org/licenses/ by-nc-nd/4.0/).

(C) 2020 The Japanese Society of Internal Medicine Intern Med 59: 1855-1860, 2020 